\title{
Undergraduate Medical Curriculum of Universiti Sains Malaysia in terms of Harden's Ten Questions of Curriculum Development
}

\author{
Hafiza Arzuman
}

\begin{abstract}
Introduction
The School of Medical Sciences (SMS) of Universiti Sains Malaysia (USM) has developed its curriculum to produce professional medical practitioners to meet the national requirement besides enhancing the medical services. It makes every effort to be the centre of academic excellence, leader in research and innovation in the field of medical sciences and technology. The medical school of USM is the pioneer to adopt an innovative SPICES strategy which features student centered, problem based, integration, community orientation and a spiral approach in its implementation (Harden \& Stamper, 1999). The spiral concept enables the school to implement the horizontal and vertical integration of different disciplines.
\end{abstract}

The block based spiral curriculum with three Phases makes it distinctive from other medical program of the country. The Community and Family Case Study (CFCS) program provides community orientation, another unique aspect of the curriculum. It also allows an encouraging educational environment which profoundly influences the outcome of the program (Arzuman et al, 2010). A curriculum is a combination of idealism and realism, which is not viewed as an aggregate of separate subjects but rather as a programme of study where whole is greater than the sum of the parts (Harden, Davis \& Crosby, 1997). This philosophy underlines the medical curriculum which emphasized the combination of different approaches in its development specially the aims and objectives (engineering approach),

Corresponding author

Dr. Hafiza Arzuman (MPH, GrDHPEd, GrDMEd)

Senior Lecturer

Department of Medical Education

School of Medical Sciences

Universiti Sains Malaysia Health Campus

16150, Kubang Kerian

Kelantan, Malaysia

Email: hafiza.arzuman@gmail.com; hafiza@kb.usm.my

Ph: +6097676549(Off) , +60109197914 (HP) teaching strategies (mechanics approach) and content arrangement (cookbook approach), regular review by curriculum committee and subcommittees (United Nations approach) (Harden, 1986b). The newer educational strategies such as integration, student centered approach, problem based learning, electives and options, early introduction of clinical teaching and community orientation for students are all reflected in the curriculum.

The Harden's 10 questions is a practical aid of curriculum development which provides a comprehensive, user friendly frame work for curriculum development and is relevant in all situations. A well developed curriculum must address Harden's 10 questions during its developmental phase (Harden, 1986a; Malik \& Malik, 2002).

This paper describes the USM medical curriculum in terms of Hardens 10 questions of curriculum development and how it responded to these questions. The analysis of the USM medical curriculum will offer some help to others who are in the position to review, revise or develop a new curriculum.

\section{Q. 1: What are the needs in relation to the product of the training programme?}

The needs assessment is a systematic approach to setting priorities for future action and a fine grained determination of where a need is coming from, and provides clues to how the need may be reduced or eliminated (Dun et al., 1985). The needs assessment of the USM medical curriculum started with study of trends and issues in medical education which involved meetings with experts, reviewing research, reading literature reviews, visiting sites, attending conferences, and participating in study groups. To identify training needs the Delphi approach (wise men approach) was adopted by the curriculum committee of the school (Green \& Louise, 2002). 


\section{Q 2: What are the aims and objectives?}

Having identified the training needs, the curriculum addressed the aims and objectives of the curriculum. It highlighted the fact that a patient is a human in the family and community perspectively. In general, the aim of the curriculum is to 'highlight' a wider scale of awareness of medical graduates about their responsibility in a society. Besides, it emphasized on possessing a leadership criteria while also being capable of continuing their education. The curriculum emphasized on education for capability and has created a concept of an efficient medical practitioner in which a doctor upon receiving his/her degree is equipped with medical knowledge and skill to resolve individuals and community problems. (http://www.medic.usm.my/undergraduate/)

\section{Q 3: What content is included?}

The USM medical course is an integrated program with a five-year duration and divided into three Phases. Each Phase has different blocks/systems with its learning objectives and content included in each Phase based on the learning objectives of the block/system.

Figure 1: Different Phases of MD curriculum with content outline

\author{
Phase I: year 1 \\ Basic medical sciences in blocks \\ Phase II: years 2 and 3 \\ Abnormal structure, pathogenesis and pathophysiology in blocks \\ Phase III: years $\mathbf{4}$ and $\mathbf{5}$ \\ Clinical application of the Phase I \& II learning in blocks and rotational postings
}

In Phase I the identified content is the normal structures, functions and normal body mechanisms. The courses of behavioral sciences nursing, first aid, bio-ethics and communication skills are introduced as a preparation for CFCS in Phase II.

In Phase II the content is identified to correlate the students' basic knowledge acquired in Phase I to the advance knowledge of pathogenesis and pathophysiology, clinical and systemic disease of Phase II. The CFCS program is introduced as a block in year 2 for community orientation of the students.
In Phase III the content is identified for the application of the acquired Phase I and II knowledge to solve patient's problem in the individual and in the perspectives of the community. This Phase has been divided into:

- Interdisciplinary activities (general blocks)

- Rotational postings (specific blocks) and

- Self study 


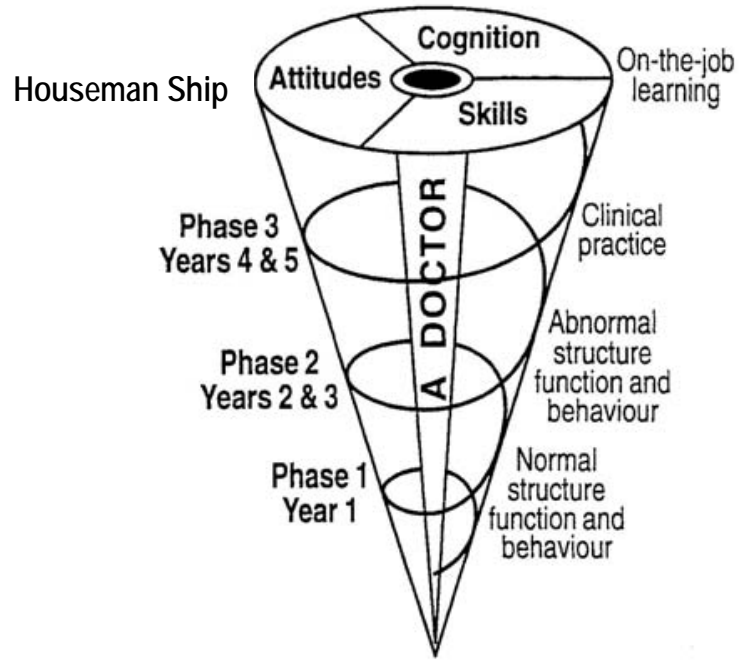

\section{Q 4: How is the content organized?}

The unique feature of the curriculum is the system based spiral arrangement of its content (Figure 2). A spiral curriculum has an iterative revisiting of topics, subjects or themes throughout the course with deepening of the content, with each successive encounter building on the previous one (Harden \& Stamper, 1999). All the three Phases of the curriculum are combined in a spiral concept with a close relationship between one Phase to the other. Learning activities in Phase I forms the first level of the spiral, it is explored in depth in Phase II and Phase III. In the curriculum students move on through different experiences and there is a chance of revisiting previous learning to re-explore and extent it, which is based on the constructivist learning approach. The content is integrated both horizontally and vertically while the spiral approach linked the theory to practice, increasing the time for clinical activities and allowing students to spend more time with patients, so they can apply their theoretical knowledge into clinical practice.

\section{Q 5: What educational strategies are adopted?}

The school adopted a mix approach with emphasis on the SPICES strategy in its curriculum implementation. In Phase I there is a horizontal integration among the basic subjects with some amount of vertical integration in nursing and first aid block. In this Phase the integration is at the level of harmonization and nesting of the integration ladder. Phase II onwards the integration moves to a higher level like temporal coordination, sharing, correlation and multidisciplinary especially, whereas in Phase III the integration to achieve the highest trans-disciplinary and inter/multidisciplinary level. (Harden, 2000).

The community orientation started in Phase II through the CFCS block which continued until year 5 as Family Medicine and Community Medicine Block. A number of areas for electives are offered by the elective committee. Students are also allowed to choose their own area of interest for elective study in year 4 elective posting.

The systemic approach is practiced in clinical teaching where each student rotates based on their postings. In hospital they rotate in outpatient and inpatient, from general to specific health problems. They also rotate to other health care sectors, community clinics and so on and are monitored by log book or $360^{\circ}$ assessment. Though the curriculum is an integrated, problem-based and systemic, there are still some amount of teacher centered approach is practiced especially in year 1 . This is because these students have insufficient knowledge about their role in student centre learning. 


\section{Q 6: What teaching methods are used?}

Lecture, demonstration, practical, fixed learning module, tutorial and early clinical contact in first aid and nursing blocks are the main educational methods with horizontal integration in Phase I. The lecture is used to introduce the newer and difficult concept to the students which tutorial sessions. Tutorial encourages students to be more active learners and make them more responsible to learn by themselves with some help from their tutors. Practicum and demonstration are mainly used for learning basic and applied anatomy, physiology, chemical pathology and basic clinical procedures like nursing care, communication skills, and first aid management. In Phase II the main teaching methods are problem based learning ( $\mathrm{PBL})$, fixed learning module, the clinical skills centre teaching (CSC), expose to real patient in the hospital and a community orientated program with some amount of lecture. Students are oriented about the process of PBL before they proceed for it. The educational methods in Phase III are reflected by:

a) integrated multidisciplinary teaching;

b) modified subject/discipline based;

c) problem based and problem solving; and

d) community oriented/based and self-study

In the self-study period students are expected to be in the library, CSC, ward, accident and emergency clinics or operation theater to know the patient socially and clinically, practice relevant clinical skills, and to discuss with peers, lecturers or any other relevant persons.

\section{Q 7: How the assessment is carried out?}

In each Phase a range of assessment methods have been adopted to assess the learning outcomes of the curriculum correctly and reliably. The assessment is carefully planned and designed so that it is reflective of the curriculum aims and objectives. There is a combination of continuous and summative assessments. The Phase I has Slide Spot Assessment (SSA) in continuous assessment to prepare students for actual Objective Structure Practical Examination (OSPE)/ Objective Structure Clinical Examination (OSCE) for summative assessment with Multiple Choice Questions (MCQs) and Short Essay Questions (SAQ). To assess students' cognitive knowledge in a wider scale the Phase II uses Structured Essay Questions (SEQ) and MCQs. The SEQ questions are structured to make it objective and constructed based on case scenario which assesses students' critical and higher order thinking ability, problem solving skills, application of knowledge and decision making skills. OSPE/OSCE are used to assess students' psychomotor and communication skills. In Phase III the continuous assessment of each block posting consists of a) attendance in different educational activities, b) satisfactory completion of log book, c) satisfactory case write-ups and end of block assessment. The end of block assessment is carried out by MCQs, Modified Essay Questions (MEQ), short and long cases, OSCE and oral test. As the course precedes, the assessment format changes from simple SAQs to SEQs to MEQs and so on to test the learning objectives accurately as per the learning experiences of the students.

\section{Q 8: How details of the curriculum are communicated?}

The details of USM medical curriculum is communicated in many ways to all stakeholders. The prospectus book includes the details of the course objectives, content and facts, entry prerequisites, resource available and other necessary information for the potential candidates. Each Phase chairperson is responsible to communicate any changes in the curriculum, timetables and other information to the teachers, students and the academic support staff. The curriculum book of each Phase has the relevant information for teachers and students. At the beginning of each Phase students are oriented thoroughly about the format of the Phase, teaching methods, assessment techniques, resource available and other information by the respective chairperson and by the Deputy Dean, Academic and Students Development. The main stakeholder, the Ministry of Health is fully informed about the curriculum and its implementation status and any changes by the concerned people.

\section{Question 9: What educational environment is fostered?}

The prevailing conducive educational environment of the medical school is favorable for its operation and profoundly influencing the outcome of the programme. It has all the support facilities for teaching and students support. The students also identified the overall educational environment of the USM medical school is comfortable for them and their social life is higher than average (Arzuman et al, 2010). 


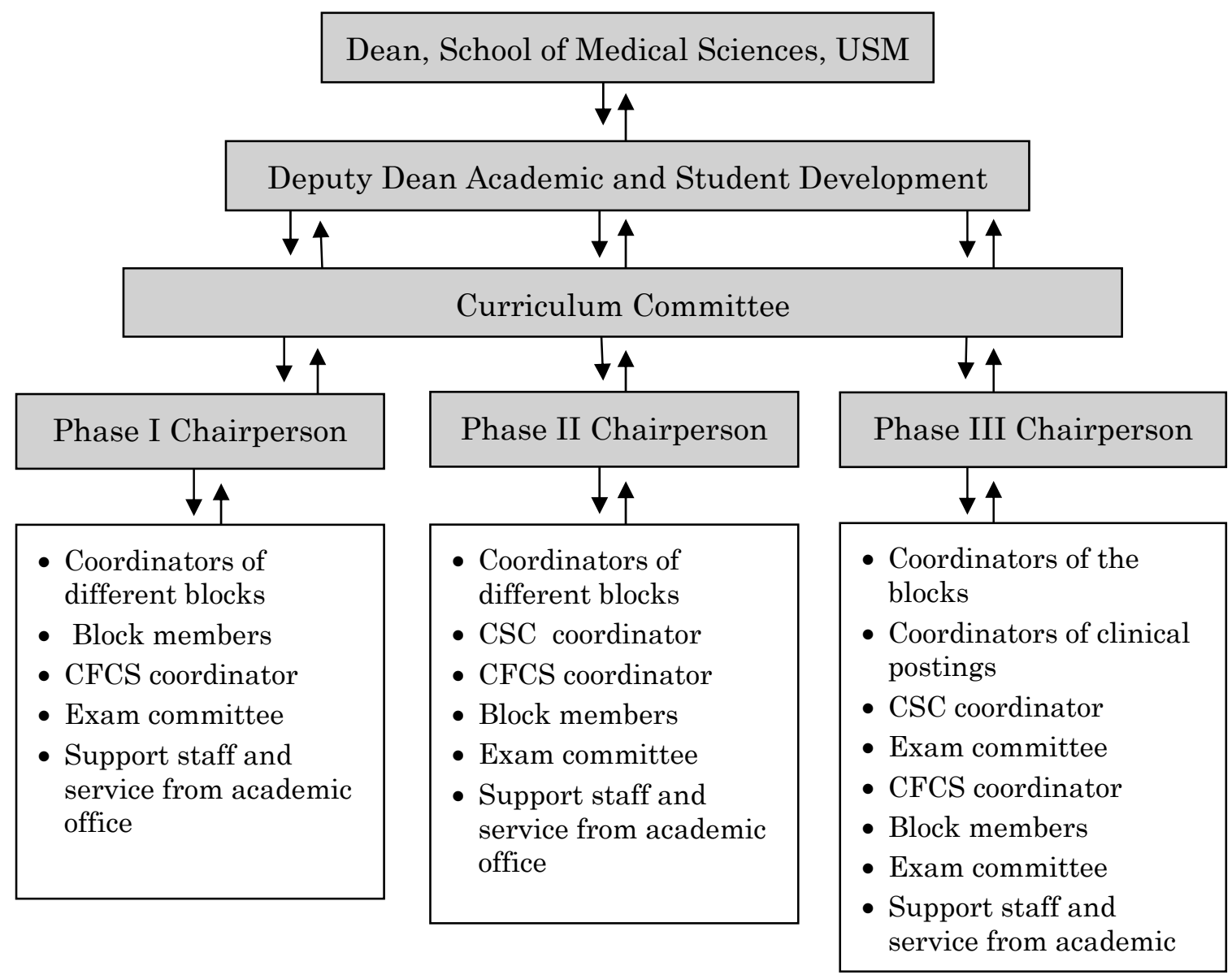

\section{Q 10: How the process is managed?}

The whole educational process is managed by the Dean of the Medical School, Deputy Dean of Academic and Student Development and the academic office of the school. The management process is shown by the figure 3

\section{Conclusion}

The USM medical course is a multi-discipline educational system which successfully addressed Harden's 10 questions and thereby fulfilled the criteria of a well developed curriculum. The significant features of the curriculum are integration of teaching and organ-base education system focusing on SPICES strategy. The Medical School is committed to enhance the competitive nature of its students and promoting their intellectual and educational quests, providing confidence for continuing study and a sense of social accountability.

\section{Conflicts of interest}

The author reports no conflict of interest. The author alone is responsible for the content and writing of the paper.

\section{References}

Arzuman, H., Yusoff, M.S.B. \& Chit, S.P. (2010) Big Sib Students' perceptions of the educational environment at the School of Medical Sciences, Universiti Sains Malaysia, using Dundee Ready Educational Environment Measure (DREEM) Inventory, Malaysian Journal of Medical Sciences, 17, 3, pp. 40-47.

Dunn, W.R., Hamilton, D.D. \& Harden, R.M. (1985) Techniques of identifying competencies needed of doctors, Medical Teacher, 7, 1, pp. 15-25.

Green, D. \& Louise D. (2002). How should we best train clinical psychology supervisors? A Delphi survey, Psychology Learning and Teaching, 2, 2, pp.106-115. 
Harden, R.M. (1986a) Ten questions to ask when planning a course or curriculum, Medical Education, 20, 4, pp. 356-65.

Harden, R.M. (1986b) Approaches to curriculum planning, Medical Education, 21, pp. 458-466.

Harden, R.M. (2000) The integration ladder - A tool for curriculum planning and evaluation, Medical Education, 34, pp. 551-557.

Harden, R.M., Davis M. H. \& Crosby J.R. (1997) The new Dundee medical curriculum: a whole that is greater than the sum of the parts. Medical Education, 31(4), pp. 264-71.
Harden, R.M., \& Stamper, N. (1999) What is spiral curriculum? Medical Teacher, 21, 2, pp.141143.

Malik, A. S. \& Malik, R. H. (2002) The undergraduate curriculum of Faculty of Medicine and Health Sciences, Universiti Malaysia Sarawak in terms of Harden's 10 questions, Medical Teacher, 24, 6, pp. 616-621.

School of Medical Sciences, Undergraduate curriculum aims, [online], available at: http://www.medic. usm.my/undergraduate/ (accessed on April 27, 2010). 